\title{
Gas-Cooled Fast Reactor: A Historical Overview and Future Outlook
}

\author{
W. F. G. van Rooijen \\ Nuclear and Radiological Engineering Program, Georgia Institute of Technology, 801 Ferst Dr. NW, Atlanta, GA 30332, USA
}

Correspondence should be addressed to W. F. G. van Rooijen, vanrooijen@mail.gatech.edu

Received 18 January 2009; Accepted 7 April 2009

Recommended by Guglielmo Lomonaco

\begin{abstract}
A review is given of developments in the area of Gas-Cooled Fast Reactors (GCFR) in the period from roughly 1960 until 1980. During that period, the GCFR concept was expected to increase the breeding gain, the thermal efficiency of a nuclear power plant, and alleviate some of the problems associated with liquid metal coolants. During this period, the GCFR concept was found to be more challenging than liquid-metal-cooled reactors, and none were ever constructed. In the second part of the paper, we provide an overview of the investigations on GCFR since the year 2000, when the Generation IV Initiative rekindled interest in this reactor type. The new GCFR concepts focus primarily on sustainable nuclear power, with very efficient resource use, minimum waste, and a very strong focus on (passive) safety. An overview is presented of the main design characteristics of these Gen IV GCFRs, and a literature list is provided to guide the interested reader towards more detailed publications.
\end{abstract}

Copyright ( 2009 W. F. G. van Rooijen. This is an open access article distributed under the Creative Commons Attribution License, which permits unrestricted use, distribution, and reproduction in any medium, provided the original work is properly cited.

\section{Fast Reactors: Background and History}

Uranium as it occurs in nature contains $0.7 \%$ of the fissile isotope U-235, the rest being U-238. If bombarded with neutrons, U-238 can capture a neutron and transmute to the isotope of plutonium $\mathrm{Pu}-239$, which is fissile. Thus there is a possibility to create fissile material in a nuclear chain reacting system, and maybe even the opportunity to create more fissile material than is being consumed in the reactor: one can breed fissile material (e.g., $\mathrm{Pu}$-239) from fertile material (e.g., U-238). The number of new neutrons released by a fissile nucleus upon absorption of a neutron is given by the parameter $\eta$ :

$$
\eta=\frac{\nu \sigma_{f}}{\sigma_{a}}
$$

To maintain a critical reactor, one needs exactly one new neutron per fission, leaving $\eta-1$ neutrons to bombard a fertile material. This number of available neutrons can be interpreted as the breeding potential of a given isotope. In practice, neutrons are lost from the system by leakage, and by parasitic capture (i.e., capture in nonfuel and nonfertile materials, such as coolant and structural components). Thus, one is left with the number of available neutrons equal to

$$
\text { no. }=\eta-1-\text { leakage }- \text { parasitic capture }
$$

for fertile to fissile transmutation reactions. The factor $\eta$ is illustrated in Figure 1 as a function of the energy of the neutron causing fission. In general, $\eta$, and thus the breeding potential, is highest in fast spectrum systems, especially if the fissioning isotope is $\mathrm{Pu}-239$ or $\mathrm{Pu}-241$. At the same time, the capture cross-section of non-fuel isotopes generally decreases with energy. Thus, if one can construct a nuclear reactor in which the neutrons remain at high energy, one can minimize the parasitic losses and obtain a breeder reactor.

The potential of breeding fissile isotopes in fast reactors was recognized during the Manhattan Project, and in 1946 the first fast reactor, called Clementine, was constructed and operated at Los Alamos National Laboratory in the US. At that time, enrichment technology was still in its infancy, and the global reserves of uranium were thought to be small. It was generally accepted that there would not be enough natural uranium for a sizable fleet of civilian nuclear power plants. As a result, a feverish development program into Fast Breeder Reactors followed, leading to the start of 


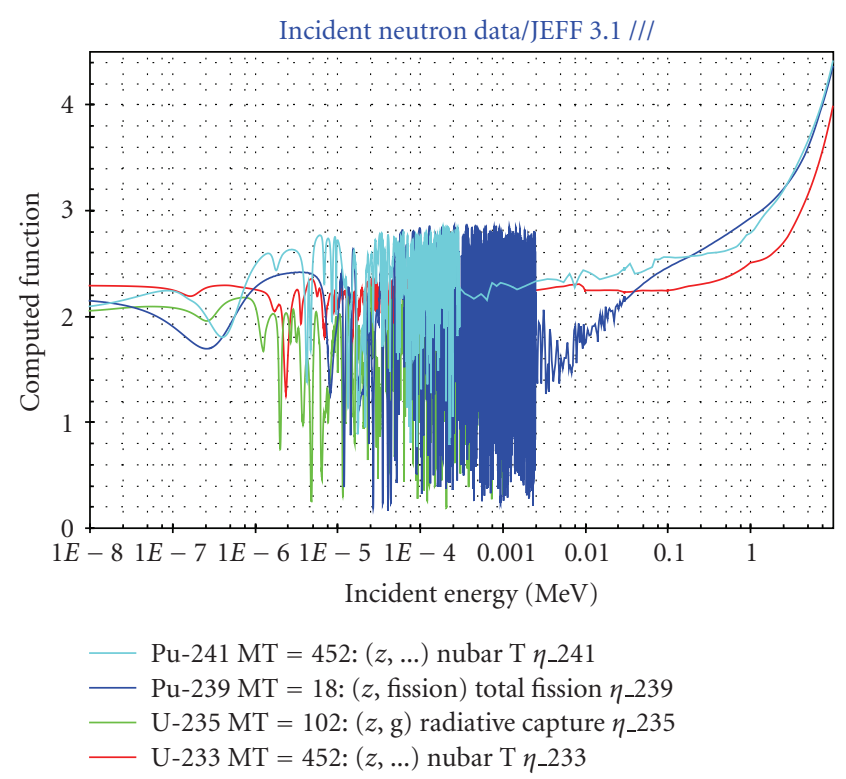

Figure 1: The $\eta$-factor for U-233, U-235, Pu-239, and Pu-241. Made with the JANIS data viewer (http://www.nea.fr/janis), based on JEFF-3.1 data. Note that U-235 has the lowest $\eta$ of all isotopes in both the thermal and the fast range. For Pu-239, the breeding potential rapidly increases above $50 \mathrm{keV}$.

Experimental Breeder Reactor (EBR-I) in 1951 at the Idaho National Lab in the US. This reactor was the first reactor to produce electricity from nuclear power. The net breeding of fissile material was confirmed in EBR-I.

After the Atoms for Peace speech (1953), many industrialized nations embarked on a Fast Breeder Reactor research program for civilian applications, of which the most notable programs were in the Soviet Union, the UK, France, Germany, and Japan. In the following decades, several fast neutron test reactors and prototype power plants were constructed worldwide. But in the 1970s the situation for fast reactors changed; advances in enrichment technology made enrichment cheaper; fast reactors would always be more expensive than LWRs, and their engineering and safety aspects significantly are more challenging; uranium was more abundant than originally thought; and the nuclear power industry did not grow at the expected high rate. In the US, the decision in the late 1970s to disallow reprocessing in the civilian fuel cycle signified the end of any fast breeder reactor applications in the USA. In the 1990s, almost all major fast reactor programs in the world were either cancelled or significantly downsized. The interested reader is referred to the IAEA Fast Reactor Database for an overview of past fast reactor experiences worldwide (http://www.iaea.org/inisnkm/nkm/aws/frdb/index.html ) .

Presently, fast reactors are gaining increasing attention for several reasons. If nuclear power is to grow significantly in the future, uranium will become scarce. Fast reactors can contribute to sustainable development by using a much larger fraction of the uranium resources. On the other hand, the high number of excess neutrons available in a fast reactor allows their application as actinide transmutation reactors, to reduce the long-term radiotoxicity of nuclear waste.

\section{Engineering Choices for Gas-Cooled Fast Reactors}

To obtain the highest breeding potential in any reactor, the amount of parasitic absorption should be minimized. This translates into the choice of a very tightly packed core in which the volume fractions of structural materials and coolant are kept to a minimum, commonly featuring a triangular lattice for the fuel pins. The number of capture reactions producing fissile material per unit time is proportional to the flux level in the reactor. For reasons of economics and fuel cycle characterestics, it is generally desirable to have the highest possible breeding rate, and thus generally the reactor core is designed to have a very high flux level. This high flux level generally translates into a very high fission rate, and as a result the power density in a fast reactor core is usually very high, typically of the order of $300 \mathrm{MW} / \mathrm{m}^{3}$, which is 3 to 4 times higher than in LWRs. It should be noted that the high power density in a fast reactor is a result of design choices rather than an innate feature of this type of nuclear reactors.

The choice of coolant is dictated by the desire to introduce the smallest amount of absorption and moderation, while still being able to reliably remove the heat from this high power density configuration. Commonly a liquid metal is chosen, with sodium being the most common, but a gas coolant is also possible. The most common choices for gas-cooled fast reactors are helium, (supercritical) $\mathrm{CO}_{2}$, and steam. (Special mention should be made of the supercritical water-cooled reactor concept, which is proposed with thermal, epithermal, and fast neutron spectra.) Even though all these coolants are composed of light isotopes, the amount of moderation is limited because of the low number density of gas coolants. In comparison with sodium, gas coolants have the following advantages for fast reactor applications.

(1) Chemical compatibility with water, obviating the need of an intermediate coolant loop, and generally good chemical compatibility with structural materials.

(2) Negligible activation of coolant.

(3) Optically transparent, simplifying fuel shuffling operations and inspection.

(4) Gas coolants cannot change phase in the core, reducing the potential of reactivity swings under accidental conditions.

(5) Reduction of the positive void effect typically associated with sodium.

(6) Gas coolants generally allow a harder neutron spectrum, which increases the breeding potential of the reactor. 
TABle 1: Design data for four early GCFR proposals. The small General Atomics GCFR was envisaged as a prototype, the GBRs were envisaged as large-scale commercial systems. From the three GBR concepts, the GBR-4 was adopted as the reference design. Note: pressure drop is over entire primary circuit for GA design; core only for GBR designs.

\begin{tabular}{|c|c|c|c|c|}
\hline Reactor & GA GCFR & GBR-2 & GBR-3 & GBR-4 \\
\hline Coolant & $\mathrm{He}$ & $\mathrm{He}$ & $\mathrm{CO}_{2}$ & $\mathrm{He}$ \\
\hline Thermal power [MW] & 835 & 3000 & 3000 & 3450 \\
\hline Fuel type & pins & particle & particle & pins \\
\hline Fuel material & $\mathrm{UPuO}_{2}$ & $\mathrm{UPuO}_{2}$ & $\mathrm{UPuO}_{2}$ & $\mathrm{UPuO}_{2}$ \\
\hline$T_{\text {core, in }}\left[{ }^{\circ} \mathrm{C}\right]$ & 323 & 260 & 260 & 260 \\
\hline$T_{\text {core,out }}\left[{ }^{\circ} \mathrm{C}\right]$ & 550 & 700 & 650 & 560 \\
\hline Pressure $[\mathrm{MPa}]$ & 8.5 & 12.0 & 6.0 & 12.0 \\
\hline Pressure drop [MPa] & 0.37 & 0.34 & - & 0.24 \\
\hline Core height $[\mathrm{m}]$ & 1.0 & 1.0 & 1.0 & 1.4 \\
\hline Core diameter $[\mathrm{m}]$ & 2.0 & - & - & - \\
\hline Breeding Gain & 0.4 & 0.43 & 0.36 & 0.42 \\
\hline Year of design data & 1974 & 1972 & 1972 & 1974 \\
\hline
\end{tabular}

(7) Since gas coolants have a low number density, one can allow a larger coolant fraction in the core without an unacceptable increase in parasitic capture. This more "open" core arrangement increases neutron leakage into the breeding blankets, improving the breeding gain.

Disadvantages of gas coolants include the following.

(1) Higher pumping power compared to liquid coolants.

(2) Need to maintain high pressure in the system, typically around $7 \mathrm{MPa}$ for helium systems, to approximately $25 \mathrm{MPa}$ for supercritical $\mathrm{CO}_{2}$ (cf. PWR $15 \mathrm{MPa}$ ). For GCFRs, the operating pressure is chosen based on a tradeoff between pumping power (higher pressure is better), engineering reasons (lower pressure is easier and cheaper), and safety (higher operating pressure means larger depressurization effects).

(3) Gas coolant properties generally require artificial roughening of the cladding to maintain acceptable cladding temperature, resulting in an increased pressure drop over the core, and a higher requirement on pumping power. Besides, in a fast reactor the power densities of individual subassemblies vary considerably. To maintain adequate temperatures, either each assembly need to have an adjustable flow gag, or the amount of roughening of the cladding can be varied.

(4) High coolant flow velocity can lead to significant vibrations of the fuel pins.

(5) Decay heat extraction from the high power density core is difficult, becoming more so following a depressurisation event, requiring fast response and high reliability and, in the latter case, large pumping power.

In practice, the advantages of a simpler system layout in GCFRs, a higher breeding gain, and higher thermal efficiency are offset by the need of the engineered safety precautions for depressurization. In practice the temperature limits on conventional cladding material (stainless steel) do not allow operation at much higher temperature than in a typical sodium-cooled fast reactor. Overall, the economics of GCFRs were never shown to be better than Liquid Metal-cooled FBRs. No GCFRs were ever constructed, and the "classic" GCFR concept was abandoned in the late 1970s.

\section{Overview of Past GCFR Programs}

In what follows an overview is presented of the major GCFR programs which occurred in the past. This overview is not meant to be exhaustive, but rather it serves to illustrate that the GCFR concept has been well researched in the past. For more information, the reader is referred to [1].

3.1. Germany: The Gas Breeder Memorandum. In Germany the nuclear research establishments at Karlsruhe and Jülich, together with partners from industry, prepared a document on Gas Breeder Reactors known as the Gas Breeder Memorandum (“Gasbrüter-Memorandum”, 1969 [2]). This memorandum defined 3 GCFR designs, all featuring helium cooling. Steam and $\mathrm{CO}_{2}$ were reviewed as coolant candidates but deemed inadequate. In the Gas Breeder Memorandum the main focus was on a conventional core, with the fuel assembly design extrapolated from an LMFBR design, and a Prestressed Concrete Reactor Vessel (PCRV) extrapolated from thermal HTR, with pin-type fuel, stainless steel cladding, and a secondary steam cycle. All blowers and steam generators are integrated into the PCRV. Limited research was done into a direct-cycle reactor, and into coated particle fuel, although the two were not necessarily combined into one concept. Some design data can be found in [2]. The German GCFR design reached a considerable level of detail, with material irradiations planned in the BR-2 reactor in Mol (Belgium) in the mid to late 1970s. The German design is interesting because it already emphasized the need of keeping an elevated backup pressure ( 2 to 3 bar overpressure) around 


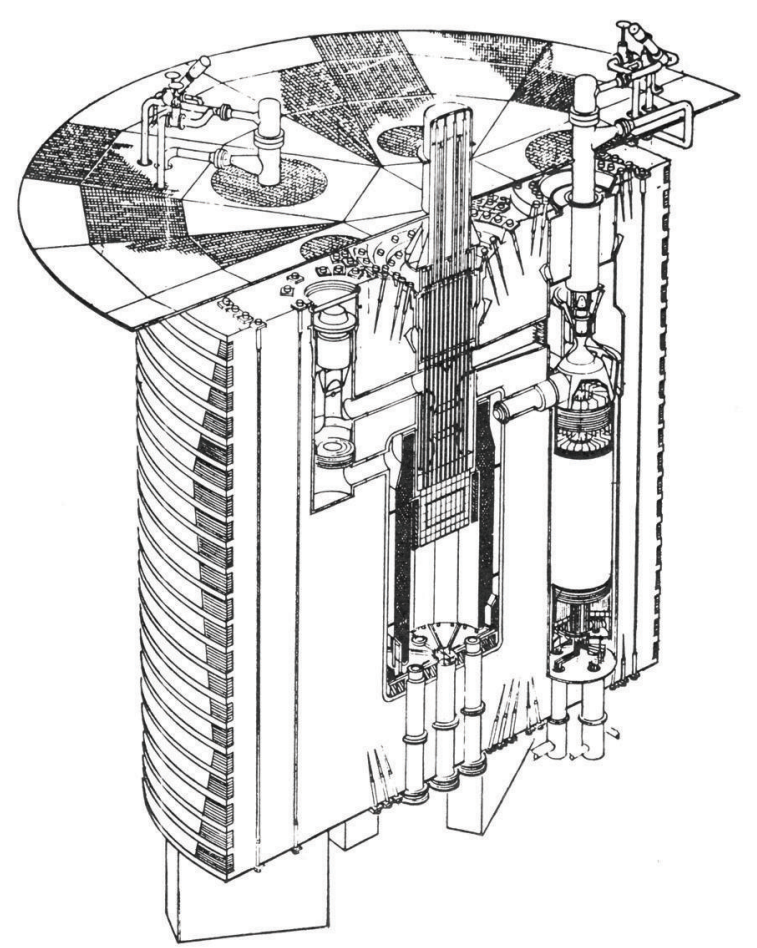

Figure 2: Primary system layout for the General Atomics GCFR Demonstration plant. The core cavity is shown empty. The overall system layout is typical for all gas-cooled reactor designs of the era. The large cavity on the right side of the core contains a boiler and a blower. The smaller cavity on the left side houses one of the active DHR systems. Figure reproduced from [4].

the primary system after a Loss Of Coolant Accident (LOCA) in order to more efficiently cool the core.

3.2. US: General Atomics. In the US, General Atomics announced plans for a GCFR in 1962. GA prepared designs for a 300 MWe demonstration plant and a 1000 MWe commercial plant [3]. In 1968 the GCFR Utility Program was started to design, license, and build a $300 \mathrm{MWe}$ demonstration plant [4]. In 1973 the target was set for the GCFR to start operation in 1983. The main parameters of the $300 \mathrm{MWe}$ GCFR are given in Table 1, and an illustration of the plant layout is given in Figure 2 (taken from [4]). The GA design has helium coolant and $\mathrm{UO}_{2}$ fuel in stainless steel cladding. The entire core is based on LMFBR technology with slight adjustments for the gaseous coolant. The fuel pins are roughened to enhance heat exchange. The primary system is housed in a PCRV, into which all blowers and steam generators are integrated. A last reference to the GA GCFR demonstration design was found in 1981, when the power output was increased to $350 \mathrm{MWe}$, but the safety case remained problematic [5].

3.3. Europe: The Gas Breeder Reactor Association. In Europe a number of players in the nuclear field joined forces to develop a gas-cooled fast reactor; the Gas Breeder Reactor Association. This group proposed a first design (GBR-1) in

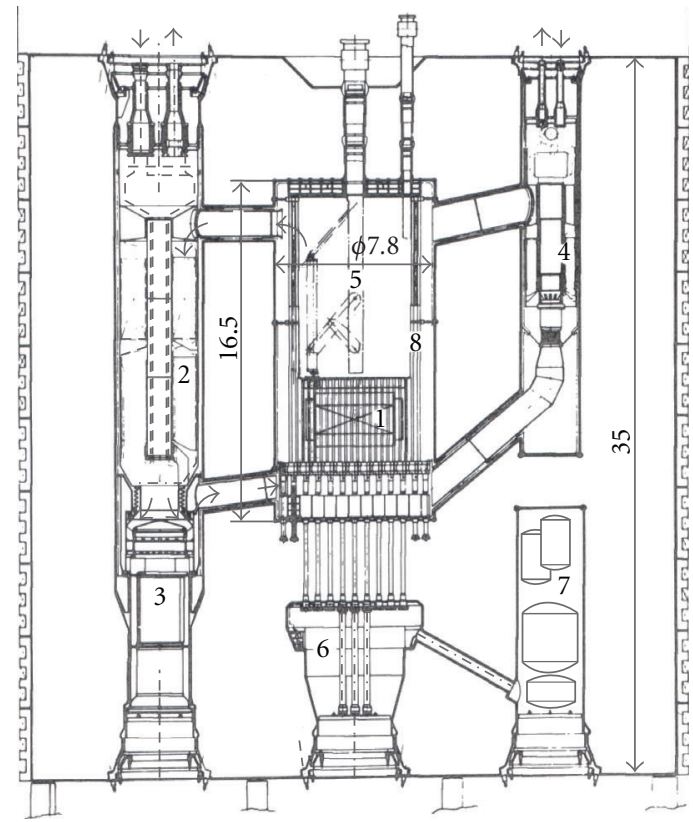

Figure 3: Vessel cross section of the PCRV for GBR-4 (1200 MWe). All dimensions in $\mathrm{m}$. 1: core, 2: main steam generator, 3: main gas circulator, 4: emergency cooling loop, 5: fuel manipulator, 6: control cavity, 7: helium purification plant, 8: neutron shield.

1970, a 1000 MWe reactor featuring helium coolant, pin-type fuel, conventional outlet temperature, and a secondary steam cycle. This design was followed by GBR-2 and -3 (1971), also 1000 MWe reactors but using coated particle fuel, slightly elevated outlet temperature, and helium coolant for GBR-2; $\mathrm{CO}_{2}$ coolant for GBR-3 [6]. The 3 designs finally evolved into the GBR-4 design, a 1200 MWe reactor with helium cooling and pin-type fuel. Table 1 lists the main design data for GBR2, -3 , and -4 . Like other designs of the era, the core, blowers, and steam generators were integrated into a PCRV. A crosssection of the GBR-4 PCRV is shown in Figure 3.

For GBR-2 and GBR-3 detailed designs were prepared of the coated particles, and two designs were proposed for the fuel assemblies to hold the coated particles. The fuel assemblies for GBR-2 (helium coolant) and GBR-3 $\left(\mathrm{CO}_{2}\right.$ coolant) are illustrated in Figure 4. For GBR-2, each fuel assembly consists of 7 fuel cylinders. Each fuel cylinder consists of 2 perforated concentric annuli with coated particles packed between them. Helium flows inward to keep a compressive stress on the inner tube. The inner tube would have been made in $\mathrm{SiC}$, while other parts would be stainless steel.

The GBR-3 assembly consists of a "stack of saucers". The coolant flows up through the central cylinder, then flows radially through the bed of coated particles, then flows up and out of the core. The cold parts are made of steel, and hot parts of SiC. The fuel assembly for the GBR-4 design is less ambitious, and is based on an LMFBR fuel assembly with pin fuel. An overview of the GBR-4 fuel assembly features is given in Figure 5, because it is very typical of all GCFR fuel pins designs of that time. Each fuel pin holds 
GBR-2 fuel assembly

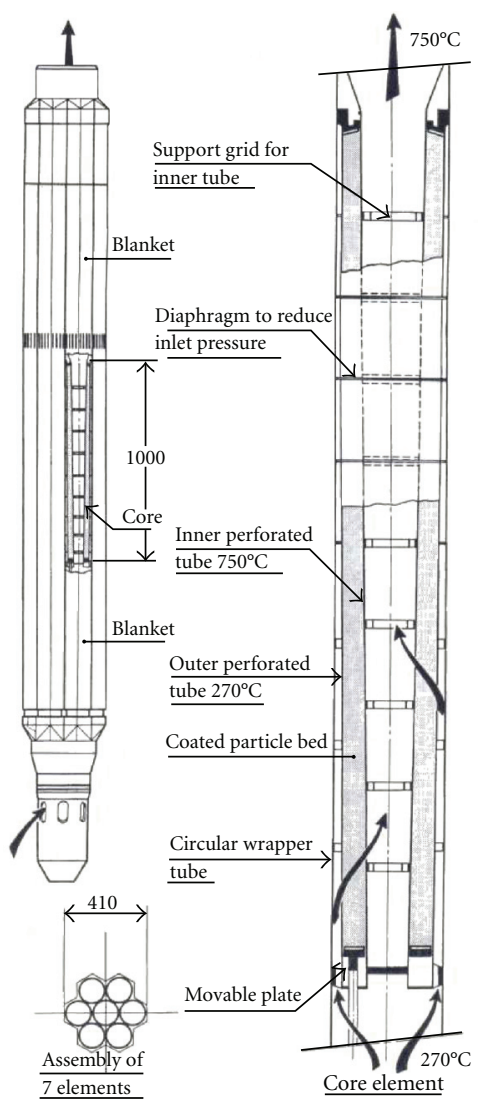

GBR-3 fuel assembly

Coolant at $700^{\circ} \mathrm{C}$

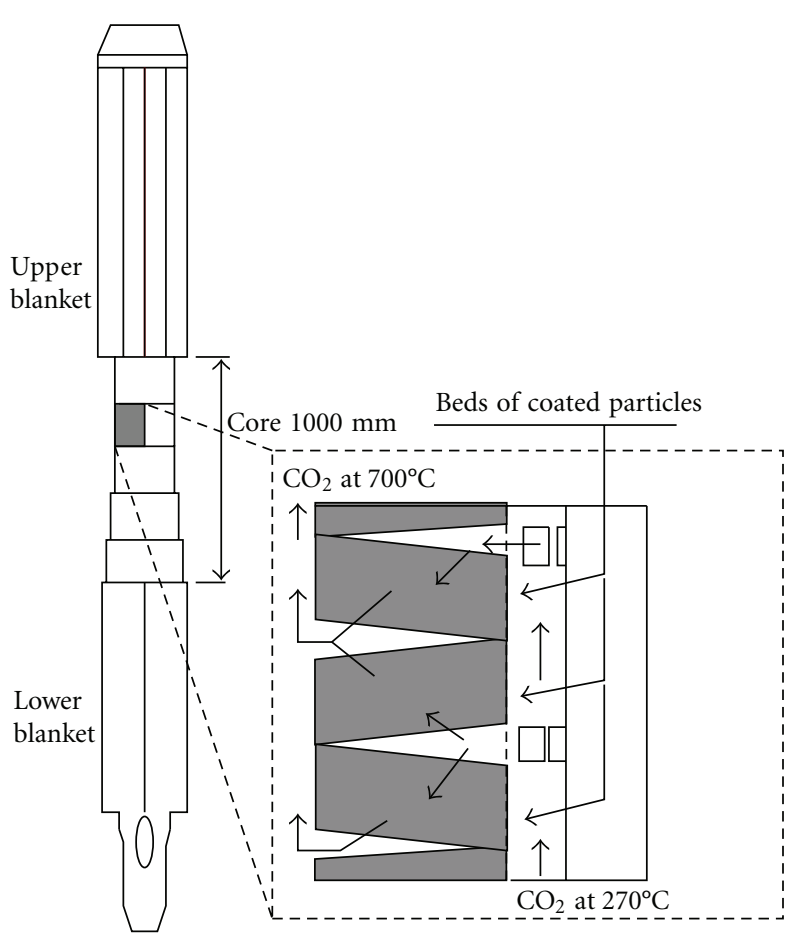

$\mathrm{CO}_{2}$ at $260^{\circ} \mathrm{C}$

FIGURE 4: Fuel assemblies for GBR-2 (left) and GBR-3 (right).

a number of traditional MOx pellets. Surface roughening enhances turbulence and heat transfer. The high helium velocity requires many restraining devices to prevent the fuel pins from vibrating too violently. Spacer wires, traditionally used in fast reactors, are not strong enough. Thus grid spacers are used, which have a very intricate design to be strong enough and not introduce too much drag.

The GBR-2 design is interesting because it resurfaces in modern design proposals for GCFRs, for instance, in Japan [7]. The objective of the coated particle fuels was to increase the core outlet temperature to improve the thermodynamic efficiency of the secondary steam cycle. For both GBR-2 and -3 coated particles were only used for the driver fuel, the blankets employed traditional pintype fuel. This solution was chosen because at the time of design reprocessing of coated particle fuel was not proven. GBR-2 and -3 required several ceramic parts, most notably the structures at the outlet side. The fabrication difficulties related to large ceramic parts led to the development of GBR4, which is a much more conventional design. In GBR-4, the outlet temperatures are decreased, enabling the use of stainless steel components throughout the core. The plant efficiency is lower, which is offset by a larger total output of the reactor: from $1000 \mathrm{MWe}$ to $1200 \mathrm{MWe}$. A last reference to the GBR-4 design was found in [8], where the safety case for large GCFR cores is discussed.
3.4. The Soviet Union: Dissociating Coolant. In the Soviet Union a GCFR programme was initiated focusing on a dissociating coolant: $\mathrm{N}_{2} \mathrm{O}_{4}$. In the core the $\mathrm{N}_{2} \mathrm{O}_{4}$ would dissociate through two endothermic chemical reactions [9]:

$$
\mathrm{N}_{2} \mathrm{O}_{4} \rightleftharpoons 2 \mathrm{NO}_{2} \rightleftharpoons \mathrm{N}_{2}+2 \mathrm{O}_{2} \text {. }
$$

Operating temperature was comparable to those of other contemporary GCFR designs, with a somewhat higher pressure (between $16 \mathrm{MPa}$ and $25 \mathrm{MPa}$ ). The major advantage of the dissociating coolant lies in the possibility of condensing the working fluid in the heat exchanger, thereby greatly reducing the pumping power. The system operates much like a refrigerator. Also the combined effects of evaporation and a chemical reaction absorb a large amount of heat from the core, so the mass flow of coolant can be relatively small. The $\mathrm{N}_{2} \mathrm{O}_{4}$ coolant is very corrosive. This problem was solved by the development of chromium dispersion fuel pins in the late 1970s (small inclusions of $U$ metal or $\mathrm{UO}_{2}$ in a matrix of chromium) and extensive research into the corrosion behavior of various steel types [10]. This last paper also mentions irradiation experiments on the chromium dispersion fuel pins in a test rig using $\mathrm{N}_{2} \mathrm{O}_{4}$. As with other GCFR programs, no references are found later than the early 1980s.

3.5. UK: $E T G B R / E G C R$. In the late 1970 s a UK program was initiated into an "Existing Technology Gas Breeder Reactor" 


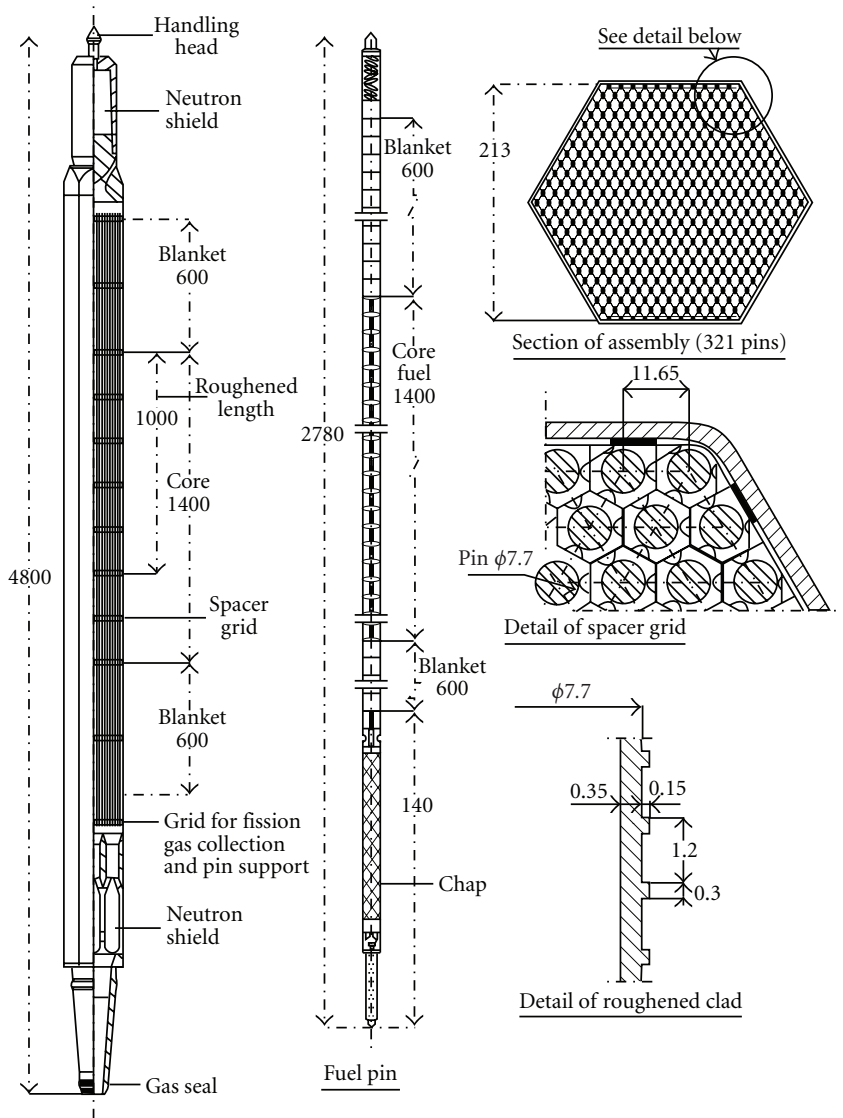

FIgURE 5: Overview of the GBR-4 fuel assembly. An example of roughened cladding is in the lower right figure.

(ETGBR). This design focused on joining the experience gained in the UK on sodium systems (PFR, Dounreay) and the thermal $\mathrm{CO}_{2}$-cooled AGR reactors. The fuel assemblies used stainless steel cladding with surface roughening, while the entire system was to be housed in a concrete vessel as used for the AGRs. ETGBR used $\mathrm{CO}_{2}$ coolant, and had a lower power density than LMFBRs, with the expected higher breeding gain to make up for the difference [11]. The ETGBR is not very different from other designs of the same era for GCFRs. However, the ETGBR idea lingered on for a long time well into the late 1990s. At that late stage, the ETGBR was rebranded as the Enhanced Gas-Cooled Reactor (EGCR). EGCR was proposed as an actinide burner, first within the European Fast Reactor (EFR) program, and later in the CAPRA/CADRA study [12]. By then the reactor featured $3600 \mathrm{MWth}, \mathrm{CO}_{2}$ cooling, and nitride fuel in fuel pins.

3.6. Japan: Prismatic Fuel. In Japan a fast reactor programme was initiated in the 1960s, including sodium and gas-cooled reactor concepts. Kawasaki Heavy Industries (KHI) investigated GCFR concepts cooled with steam, $\mathrm{CO}_{2}$, and helium [13]. The helium concept was based on LMFBR technology, but KHI opted for a very low core, to reduce the pumping power requirements. The flat core also increases breeding gain but requires a larger fissile fraction. Investigations into the GCFR concept seem to have continued without interruption in Japan, culminating in the late 1990s in a GCFR design proposal by JNC. This reactor also features a core with a low height/diameter ratio "pancake core", and uses coated particle fuel. A nitride fuel compound is chosen for the kernels. Buffer layer and sealing layers are made of TiN. Two types of fuel assemblies are proposed. One fuel assembly resembles that of GBR-2: coated particles are arranged in an annular bed, with the helium flowing radially through the bed. The other design features large prismatic blocks filled with a mixture of coated particles and a matrix material ( $\mathrm{TiN}, \mathrm{SiC}$ or $\mathrm{ZrC}$ ). Coolant channels run axially through the blocks. All structural parts are made in $\mathrm{SiC}$. Thermal output is $2400 \mathrm{MWth}$, with a power density of $100 \mathrm{MW} / \mathrm{m}^{3}$. The coolant is helium and a direct cycle energy conversion system is envisaged [7].

\section{Generation IV and a New Start for GCFR Development}

The possible depletion of fossil fuel and the wish to limit $\mathrm{CO}_{2}$ release into the atmosphere cause a new interest in nuclear energy as the only $\mathrm{CO}_{2}$-free energy source with high capacity. There is a growing pressure from society to reduce the amount of long-lived nuclear waste material as far as possible, and to further increase the safety of nuclear power stations. These points are addressed by the Generation 


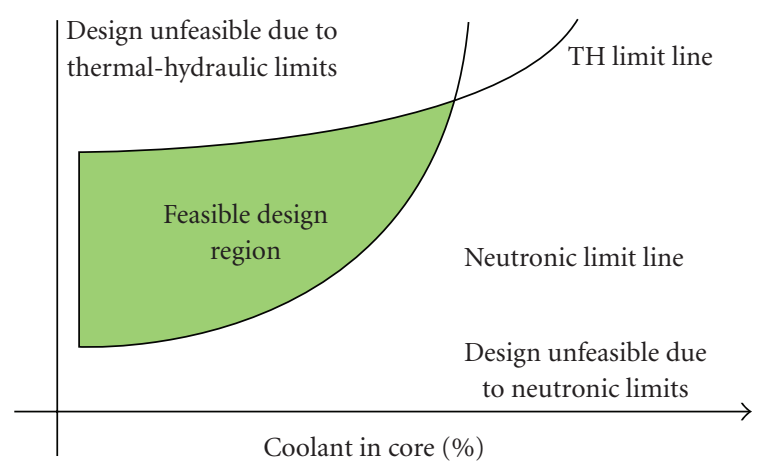

FIGURE 6: Schematic illustration showing a region of feasible GCFR designs bounded by neutronic and thermohydraulic (TH) limits. The $x$-axis gives the percentage coolant in the core.

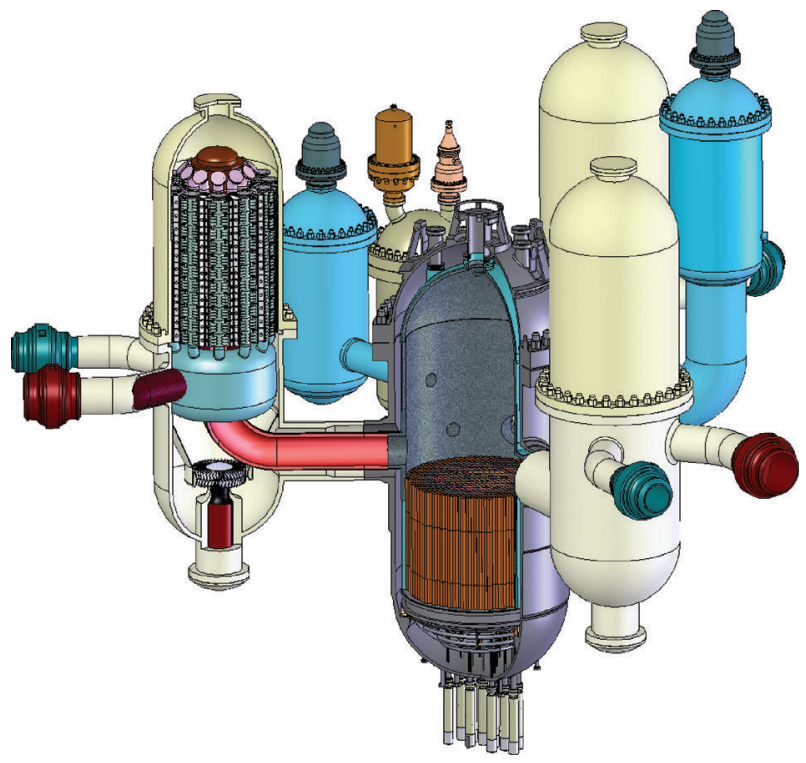

Figure 7: A cross-cut through a 2400 MWth Gen IV GCFR plant with indirect cycle operation. The large structures contain the intermediate heat exchangers. The elevated structure on the right is the decay heat exchanger. The entire system would be built into a tight-fitting secondary close containment. Image provided by [25].

IV International Forum, which is an international research initiative for the fourth generation of nuclear power plants, envisaged to enter service within the first half of the 21st century [14]. Six reactor types have been selected for further research and evaluation in the Generation IV framework, the Gas (Cooled) Fast Reactor being one of the six concepts. In the Generation IV documents, the concept is commonly referred to as "Gas Fast Reactor", abbreviated GFR, and we will follow this convention for the remainder of this paper.

The Generation IV objectives are to improve all aspects of nuclear power generation: safety and reliability, economics, sustainability, availability, and proliferation and physical protection. The six reactor types chosen all have their strong and weak points; used in a symbiotic system, the six reactor types should counterbalance their mutual weak points. There is a large surplus of reactor-grade plutonium available, and thus breeding of fissile material is no longer the primary target for the fast reactors in the short term. This enables a shift from high power density fast reactors to designs that are self-sustaining and put more emphasis on safety, especially passive decay heat removal. For completeness, the six Generation IV systems are listed here in the following.

- VHTR: Very High Temperature Reactor, graphite moderator, helium coolant, high temperature operation for direct cycle electricity production or industrial heat applications.

- SCWR: Supercritical Water Reactor (thermal, epithermal, and fast versions are under investigation).

- GFR: Gas-cooled Fast Reactor, high temperature operation using helium coolant, mainly intended for electricity production with direct or indirect cycles.

- SFR: Sodium-cooled Fast Reactor.

- LFR: Lead-cooled Fast Reactor.

- MSR: Molten Salt Reactor.

Within the Generation IV framework the GFR targets sustainability, that is, optimal use of resources while maintaining good safety and economical performance. The reference design of the Generation IV GFR features the following.

(1) Fast reactor core without fertile blankets, that is, all new fissile fuel is bred in the core. The background is that in a fertile blanket, the fissile element (e.g., Pu-239) is isotopically almost pure, which poses a proliferation concern.

(2) Breeding enough fissile material to refuel the same reactor, recycling all heavy metal, adding only fertile material; only fission products and reprocessing losses are discharged to a repository. This type of closed cycle is discussed in [15]. Scenario studies indicate that it is important to reduce the existing stockpile of minor actinides ( $\mathrm{Np}, \mathrm{Am}$, and $\mathrm{Cm}$ ) as much as possible $[16,17]$. For this reason several GFR investigations focus on the potential of irradiating extra MA in the GCFR fuel [18].

(3) The fuel specific power is comparatively low, typically around $40 \mathrm{~W} / \mathrm{gHM}$. By allowing a low specific power, the volumetric power density in the core remains limited, typically between $50 \mathrm{MW} / \mathrm{m}^{3}$ and $100 \mathrm{MW} / \mathrm{m}^{3}$, which improves the safety characteristics. To make up for the economic penalty of low specific power, a highly efficient power conversion system with a direct coupled gas turbine in a Brayton-cycle is the reference for electricity generation [19].

(4) Initial investigation centered on a unit power is of $600 \mathrm{MWth}(300 \mathrm{MWe})$ for a "modular" design, and a 2400 MWth (1200 MWe) design for a large-scale reactor. In practice, the $600 \mathrm{MWth}$ designs proved to be very challenging for neutronics and safety, and in 2006 the decision was made to pursue the $2400 \mathrm{MWth}$ design exclusively. There is no reference design for the 2400 MWth reactor; both direct and indirect cycle power conversion systems are possible, using 3 or 4 loops. At the time of writing, there is no clearly favorite design. 
TAble 2: Design data for several Generation IV GFRs, per July 2006. For all Direct Cycle reactors, helium is the preferred coolant. For the GFR600 Indirect Cycle variant, supercritical $\mathrm{CO}_{2}\left(\mathrm{~S}-\mathrm{CO}_{2}\right)$ is the secondary coolant. Note that the 600 MWth are currently no longer investigated. For the $2400 \mathrm{MWth}$ Indirect Cycle concept, various secondary cycles and working fluids are under consideration. The JAEA GFR has blankets to breed just enough new fissile material to allow operation in a closed fuel cycle.

\begin{tabular}{|c|c|c|c|c|c|c|}
\hline Concept & ETDR & GFR600 & GFR600 & GFR2400 & GFR2400 & JAEA GFR \\
\hline Power [MWth] & 50 & 600 & 600 & 2400 & 2400 & 2400 \\
\hline PCS & - & direct & indirect & (in)direct & direct & direct \\
\hline Coolant & $\mathrm{He}$ & $\mathrm{He}$ & $\mathrm{He} / \mathrm{S}-\mathrm{CO}_{2}$ & $\mathrm{He}$ & $\mathrm{He}$ & $\mathrm{He}$ \\
\hline Power density $\left[\mathrm{MW} / \mathrm{m}^{3}\right]$ & 100 & 103 & 103 & 100 & 100 & 90 \\
\hline Specific power [W/gHM] & - & 45 & 45 & - & 42 & 36 \\
\hline$T_{\text {core, in }}\left[{ }^{\circ} \mathrm{C}\right]$ & 250 & 480 & $\approx 400$ & 480 & 480 & 460 \\
\hline$T_{\text {core,out }}\left[{ }^{\circ} \mathrm{C}\right]$ & 525 & 850 & $\approx 625$ & 850 & 850 & 850 \\
\hline Core H/D & $0.86 / 0.86$ & $1.95 / 1.95$ & $1.95 / 1.95$ & $1.55 / 4.44$ & $1.34 / 4.77$ & $0.9 / 5.9$ \\
\hline Pressure $[\mathrm{MPa}]$ & 7.0 & 7.0 & 7.0 & 7.0 & 7.0 & 7.0 \\
\hline Fuel type & $\operatorname{Pins}^{(\mathrm{a})}$ & plates & plates & plates & pins & blocks \\
\hline Fuel mat. & $\mathrm{UPuO}_{2}$ & $\mathrm{UPuC}$ & $\mathrm{UPuC}$ & $\mathrm{UPuC}$ & $\mathrm{UPuC}$ & UPuN \\
\hline Struct. mat. & $\mathrm{AIM1}^{(\mathrm{b})}$ & $\mathrm{SiC}$ & $\mathrm{SiC}$ & $\mathrm{SiC}$ & $\mathrm{SiC}$ & $\mathrm{SiC}$ \\
\hline Refl. mat. & AIM1 & $\mathrm{Zr}_{3} \mathrm{Si}_{2}$ & $\mathrm{Zr}_{3} \mathrm{Si}_{2}$ & $\mathrm{Zr}_{3} \mathrm{Si}_{2}$ & $\mathrm{Zr}_{3} \mathrm{Si}_{2}$ & $\mathrm{SiC}$ \\
\hline Vol.\% c/s/f(c) & - & $55 / 20 / 25$ & $55 / 20 / 25$ & $40 / 37.6 / 22.4$ & $55 / 23 / 22$ & $25 / 55 / 20$ \\
\hline Breeding Gain & - & $-5 \%$ & $-5 \%$ & $-5 \%$ & 0 & $0.03 / 0.11^{(\mathrm{d})}$ \\
\hline
\end{tabular}

(a) Plate fuel in later stage.

(b) Austenitic Improved Material 1, a variation of 15/15Ti stainless steel (SS-316), developed especially for fast reactors (Phénix and SuperPhénix).

(c) Coolant, structural materials, fuel.

${ }^{(d)}$ Without/with blanket.

(5) Helium is chosen as the reference coolant. To obtain a high efficiency $(\eta>50 \%)$ in a Brayton-cycle using helium as the working fluid, a high reactor outlet temperature is necessary $\left(850^{\circ} \mathrm{C}\right)$, as well as elevated pressure (reference: $7 \mathrm{MPa}$ ). To enable operation at such high temperatures, ceramics rather than steel are used as the structural material ( $\mathrm{SiC}, \mathrm{Zr}_{3} \mathrm{Si}_{2}, \mathrm{TiN}$ ). A direct-cycle operating on supercritical $\mathrm{CO}_{2}$ can achieve a similar efficiency at lower temperature (typically $650^{\circ} \mathrm{C}$ ) but higher pressure $(25 \mathrm{MPa},[20,21])$. At the time of writing, only indirect cycle operation is considered seriously.

(6) The design of the core and fuel elements aims at promoting passive decay heat removal and providing adequate margins to core melt, by using refractory (high melting point) materials, and by allowing a large coolant fraction in the core. A large coolant fraction in the core increases the hydraulic diameter of the cooling channels, thereby reducing the friction pressure loss, increasing the mass flow under natural circulation. The objective is to allow decay heat extraction by passive methods during the first 24 hours following an accident. Studies into the natural convection behavior of Gen IV GFR concepts are presented for instance in $[22,23]$.

Outside of Gen IV, gas cooling has also been investigated for application to Accelerator Driven Systems (ADS) for actinide transmutation, but the consensus seems to be that a heavy liquid metal (Lead or Lead-Bismuth Eutectic) is preferred for ADS applications [24].

4.1. Basic Design Choices for the Gen IV GFR. The choice of zero breeding gain and the absence of blankets determine the fuel composition; there is only a narrow band of possible isotopic compositions that will result in a zero breeding gain. In the U/Pu fuel cycle, the fraction of U-238 has to be between $80 \%$ and $85 \%$; note here that the plutonium vector has a negligible influence on the breeding gain, as the neutron capture in U-238 is the most important contribution to replace consumed fissile isotopes. The absence of blankets means that the reactor can be approximated by a simple homogeneous cylinder of a fuel/coolant mixture (neglecting the heterogeneity introduced by different fuel batches, etc.). For a homogeneous cylindrical reactor of a given volume and fuel composition, there is a minimal height to diameter $(H / D)$ ratio, below which the reactor will never become critical due to excessive neutron leakage. On the other hand, there is also an optimal $H / D$-ratio, where neutron losses by leakage are minimized. Now assume a homogeneous, cylindrical reactor of a fixed volume. If the coolant fraction is increased, the amount of fuel in the core decreases, and thus the $H / D$ ratio must be chosen closer to the optimal value to obtain criticality. This is illustrated in Figure 6, where the "neutronic limit" is given as a function of the coolant fraction in the core. The neutronic limit is the minimum value of $H / D$ to obtain criticality with a given fraction of coolant in the core.

There is also a thermohydraulic limit on the $H / D$ ratio of the reactor. If, for the same power density and reactor volume, the $H / D$ ratio becomes larger (i.e., increase core height $H$, reduce diameter $D$ ), more power has to be transferred per coolant channel. This requires a larger coolant mass flow per coolant channel, resulting in a larger flow velocity and higher pressure drop over the core. This means that for a given fraction of coolant in the core, there is 
a maximum value of $H / D$ to stay below a given core pressure drop. This is illustrated in Figure 6 by the "TH limit".

A reactor can only be designed if the neutronic limit of $H / D$ is smaller than the TH limit, as in Figure 6. Note that the neutronic limit is not necessarily smaller than the $\mathrm{TH}$ limit, for example, the TH limit may result in an $H / D$ value too low to obtain criticality. In practice, choosing a low power density will enlarge the region of possibilities; lower power density means that it is easier to stay within $\mathrm{TH}$-limits, and at the same time the reactor volume will be larger for the same power output, giving larger neutronic margins by reduction of leakage. Ultimately the power density has to be chosen to yield a reasonable specific power taking into account economic factors and fuel cycle considerations, such as the availability of fissile materials.

\section{Typical System Designs for Gen IV GFRs}

Presently, several Gen IV GFR designs are investigated internationally. In this section, some general properties of these systems will be discussed. While direct cycle operation with a gas turbine was originally the reference design, this design proved to pose very challenging engineering problems. Therefore the indirect cycle option is presently the only seriously considered option. The reactors feature three or four power conversion loops. The wish to accommodate passive decay heat removal for a period of several hours after a depressurization translates in the need of maintaining an elevated system pressure even if the primary loop suffers a depressurization. To maintain an elevated backup pressure, the containment building can be kept sufficiently small, or a second "close containment" enveloping the primary circuit can be used. To obtain adequate flow rate by natural circulation, decay heat exchangers are located at a large elevation from the core. A proposed Gen IV GFR plant layout is illustrated in Figure 7, clearly showing the close containment ("guard vessel") and the elevated decay heat exchangers.

To improve the thermal-hydraulic performance of the GFR, a novel plate type fuel is currently under investigation. This type of fuel plate consists of a honeycomb structure, in which "pills" of fuel are embedded [26]. An illustration of a fuel plate is given in Figure 8, and a GFR fuel assembly is shown in Figure 9. The entire assembly is made from ceramic material ( $\mathrm{SiC})$. Diffusion of fission products is prevented by a metallic liner inside the fuel plate. Several proposed GFR fuel and structural materials are irradiated as part of the FUTURIX campaign in Phénix [27]. A large coolant faction is chosen in the core. To obtain criticality with a large fraction of coolant in the core, carbide fuels are selected because of their high density of heavy metal.

For completeness, a small overview is presented in Table 2 of some typical Gen IV GFR designs. In Europe a small-scale prototype reactor (ETDR, Experimental Technology Demonstration Reactor, recently upgraded to the ALLEGRO design) is under investigation (CEA/Euratom). It is a prototype GFR, intended to test and qualify materials and codes for Generation IV GFR designs. It will be started with

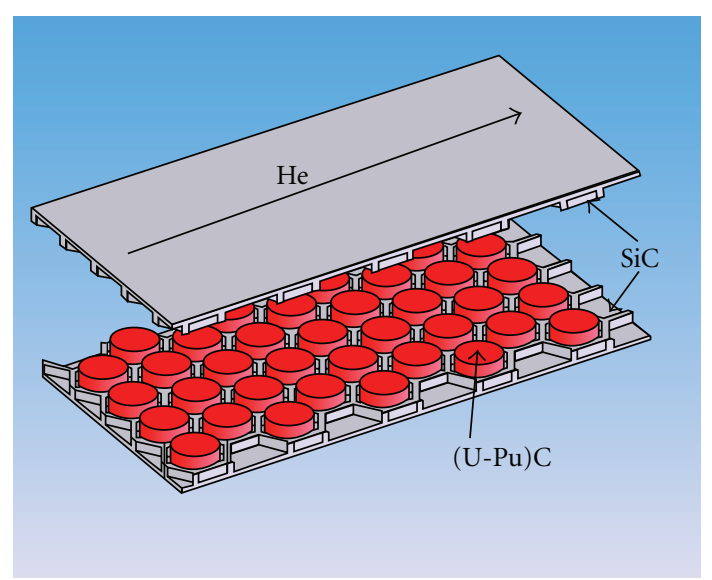

FIGURE 8: Fuel plate of Gen IV GCFR.

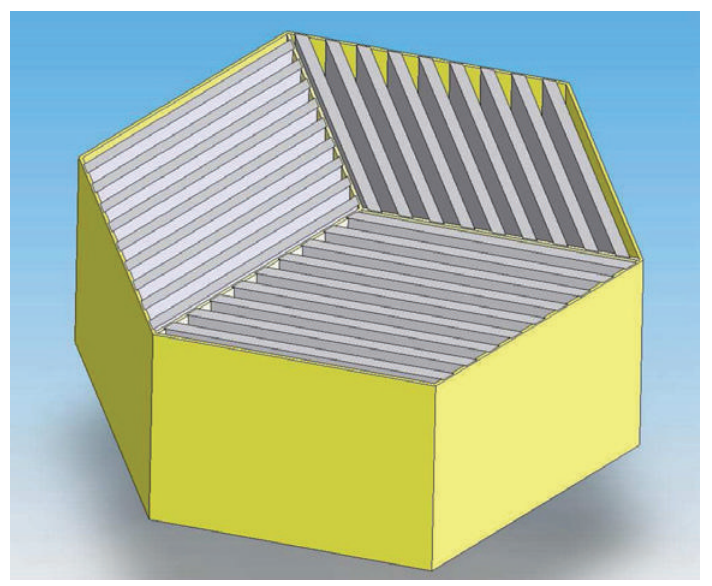

FIGURE 9: Fuel assembly of Gen IV GCFR.

a conventional core, using a pin-type MOx fuel in stainless steel cladding. The core will be gradually converted to use the ceramic fuel elements intended for Gen IV GFR. Seven proposals for large GFRs are under investigation by several research institutions within the Generation IV framework. The plate type fuel is a challenging design, and therefore pintype fuel is maintained as a backup. The present reference Gen IV GFR design is a 2400 MWth plant with indirect cycle operation, using 3 loops, each consisting of an intermediate heat exchanger and an integrated turbogenerator.

Apart from the Generation IV GFR efforts, several designs for new Gas-cooled Fast Reactors have been published in recent years. Some of these efforts originated from Gen IV related research, or in some cases were developed "in the spirit of Gen IV". To complete the overview of recent GFR developments, they deserve to be mentioned here.

Some modern GFR proposals are based on TRISO coated particle fuel. For the specific GFR fuel cycle constraints, novel particles are proposed with advanced coating layers. It is generally accepted that the pyrolytic carbon layers in HTR TRISO particles will not withstand irradiation by fast neutrons [28]. For this reason, particles with $\mathrm{ZrC}$ or $\mathrm{TiN}$ coating layers are proposed. The TRISO particles can be 
cooled directly using a fuel assembly similar to the GBR2 design discussed earlier. Other investigators focus on fuel pebbles, either with TRISO particles inside of the pebbles (e.g., the PB-GCFR, [29]), or using a novel "hollow pebble" concept, as discussed in [30, 31]. Other proposed design feature prismatic fuel blocks with coolant channels. Some designs use blocks of coated particles embedded in a matrix (e.g., [32]), or fuel blocks entirely made of fuel material (e.g., [33]). However, all these fuel designs remain highly speculative, and especially the particle- and pebble-based designs will not fulfill the safety objective of decay heat removal by natural convection.

\section{Conclusion}

Gas cooling is an option for fast reactors. Several decades ago, gas cooling was seen as an option to obtain better breeding characteristics for Fast Breeder Reactors while reducing some of the problems associated with liquid sodium as a coolant. Several designs were developed in the past, but no gascooled fast reactors were ever constructed. In recent times gas cooling is once again pursued for fast neutron systems. In these recent designs, the design focus is on sustainability. Design tradeoffs are mainly based on safety. To enable the safety level of the GCFR concept to be high, advanced fuel concepts and advanced materials will be necessary, and are currently being investigated.

\section{References}

[1] W. F. G. van Rooijen, Improving fuel cycle design and safety characteristics of a gas cooled fast reactor, Ph.D. thesis, Delft University of Technology, Delft, The Netherlands, 2006, http://repository.tudelft.nl.

[2] M. Dalle Donne and C. A. Goetzmann, "Gas-cooled fast breeder reactor design, development, and safety features," in Proceedings of the ANS Topical Meeting on Gas-Cooled Reactors: HTGR and GCFBR, American Nuclear Society, Gatlinburg, Ten, USA, May 1974.

[3] A. E. Waltar and A. B. Reynolds, Fast Breeder Reactors, Pergamon Press, New York, NY, USA, 1981.

[4] R. H. Simon, J. B. Dee, and W. I. Morita, "Gas-cooled fast breeder reactor demonstration plant," in Proceedings of the ANS Topical Meeting on Gas-Cooled Reactors: HTGR and GCFBR, pp. 336-354, American Nuclear Society, Gatlinburg, Ten, USA, May 1974.

[5] A. Torri and D. R. Buttemer, "Gas-cooled fast reactor safetyand overview and status of the U.S. program," in Proceedings of the Specialists Meeting on Gas-Cooled Reactor Safety and Licencing Aspects, pp. 1-7, IAEA, Lausanne, Switzerland, September 1980, IWGGCR-1.

[6] J. Chermanne, "Past and future programmes of the GBR Association," in Proceedings of the IAEA Study Group Meeting on Gas-Cooled Fast Reactors, pp. 78-87, IAEA, Minsk, Belarus, July 1972, IAEA-TECDOC-154.

[7] M. Konomura, T. Saigusa, T. Mizuno, and Y. Ohkubo, "A promising gas-cooled fast reactor concept and its R\&D plan," in Proceedings of the Global 2003: Atoms for Prosperity: Updating Eisenhower's Global Vision for Nuclear Energy, pp. 57-64, New Orleans, La, USA, November 2003.
[8] J. Chermanne and P. Burgsmüller, "Gas-cooled breeder reactor safety," in Proceedings of the Specialists Meeting on GasCooled Reactor Safety and Licencing Aspects, pp. 39-51, IAEA, Lausanne, Switzerland, September 1980, IWGGCR-1.

[9] G. Melese and R. Katz, Thermal and Flow Design of HeliumCooled Reactors, American Nuclear Society, La Grange Park, Ill, USA, 1984.

[10] V. B. Nesterenko, V. F. Zelensky, L. I. Kolykhan, et al., "Problems of creating fuel elements for fast gas-cooled reactors working on $\mathrm{N}_{2} \mathrm{O}_{4}$-dissociating coolant," in Proceedings of the IAEA Specialists' Meeting on Gas-Cooled Reactor Fuel Development and Spent Fuel Treatment, pp. 56-65, IAEA, Moscow, Russia, October 1983, IWGGCR-8.

[11] W. B. Kemmish, M. V. Quick, and I. L. Hirst, "The safety of $\mathrm{CO}_{2}$ cooled breeder reactors based on existing gas cooled reactor technology," Progress in Nuclear Energy, vol. 10, no. 1, pp. 1-17, 1982.

[12] R. E. Sunderland, E. K. Whyman, H. M. Beaumont, and D. P. Every, "A gas-cooled dedicated minor actinide burning fast reactor: initial core design studies," in Proceedings of the International Conference on Future Nuclear Systems (GLOBAL '99), American Nuclear Society, Jackson Hole, Wyo, USA, AugustSeptember 1999.

[13] H. Mochizuki, T. Izaki, K. Takitani, et al., "Design study of He gas-cooled fast breeder reactor," in Proceedings of the IAEA Study Group Meeting on Gas-Cooled Fast Reactors, pp. 133164, IAEA, Minsk, Belarus, July 1972, IAEA-TECDOC-154.

[14] U.S. DOE Nuclear Energy Research Advisory Committee and The Generation IV International Forum, "A technology roadmap for Generation IV nuclear energy systems," December 2002, http://gif.inel.gov/roadmap.

[15] W. F. G. van Rooijen, J. L. Kloosterman, T. H. J. J. van der Hagen, and H. van Dam, "Definition of breeding gain for the closed fuel cycle and application to a gas-cooled fast reactor," Nuclear Science and Engineering, vol. 157, no. 2, pp. 185-199, 2007.

[16] J.-P. Grouiller, L. Boucher, M. Meyer, and M. Delpech, "Application with COSI code of gen IV fast reactors introduction in the French park," in Proceedings of the International Conference on Advanced Nuclear Fuel Cycles and Systems (GLOBAL '07), pp. 1537-1542, American Nuclear Society, Boise, Idaho, USA, September 2007.

[17] Commissariat à l'Énergie Atomique, "Les déchets radioactifs à haute activité et à vie longue-recherches et résultats axe 1: séparation et transmutation des radionucléides à vie longue," Tech. Rep., CEA, Paris, France, December 2005.

[18] W. F. G. van Rooijen, G. J. van Gendt, D. I. van der Stok, and J. L. Kloosterman, "Multirecycling minor actinides in a gas-cooled fast reactor," in Proceedings of the International Conference on Advanced Nuclear Fuel Cycles and Systems (GLOBAL '07), pp. 1205-1213, American Nuclear Society, Boise, Idaho, USA, September 2007.

[19] J. C. Garnier, N. Chauvin, P. Anzieu, et al., "Feasibility study of an advanced GFR design trends and safety options status of France \& US studies," in Proceedings of the Global 2003: Atoms for Prosperity: Updating Eisenhower's Global Vision for Nuclear Energy, pp. 47-56, American Nuclear Society, New Orleans, La, USA, November 2003.

[20] Y. Kato, T. Nitawaki, and Y. Muto, "Medium temperature carbon dioxide gas turbine reactor," Nuclear Engineering and Design, vol. 230, no. 1-3, pp. 195-207, 2004.

[21] V. Dostal, P. Hejzlar, and M. J. Driscoll, "High-performance supercritical carbon dioxide cycle for next-generation nuclear 
reactors," Nuclear Technology, vol. 154, no. 3, pp. 265-282, 2006.

[22] E. Bubelis, D. Castelliti, P. Coddington, et al., "A GFR benchmark: comparison of transient analysis codes based on the ETDR concept," Progress in Nuclear Energy, vol. 50, no. 1, pp. 37-51, 2008.

[23] W. F. G. van Rooijen, J. L. Kloosterman, T. H. J. J. van der Hagen, and H. van Dam, "Lithium-6-based passive reactivity control devices for a gas-cooled fast reactor," Nuclear Technology, vol. 159, no. 2, pp. 119-133, 2007.

[24] S. Pelloni, "Static analysis of the PDS-XADS LBE and gascooled concepts," Annals of Nuclear Energy, vol. 32, no. 1, pp. 13-28, 2005.

[25] D. Poette, "Personal communication," CEA, February 2009.

[26] P. Petkevich, K. Mikityuk, P. Coddington, and R. Chawla, "Development and benchmarking of a 2D transient thermal model for GFR plate-type fuel," Annals of Nuclear Energy, vol. 34, no. 9, pp. 707-718, 2007.

[27] N. Chauvin, J. Y. Malo, J. C. Gamier, et al., "GFR fuel and core pre-conceptual design studies," in Proceedings of the International Conference on Advanced Nuclear Fuel Cycles and Systems (GLOBAL '07), pp. 423-433, American Nuclear Society, Boise, Idaho, USA, September 2007.

[28] D. G. Martin, "Considerations pertaining to the achievement of high burn-ups in HTR fuel," Nuclear Engineering and Design, vol. 213, no. 2-3, pp. 241-258, 2002.

[29] T. A. Taiwo, E. A. Hoffman, R. N. Hill, and W. S. Yang, "Evaluation of long-life transuranics breakeven and burner cores for waste minimization in a PB-GCFR fuel cycle," Nuclear Technology, vol. 155, no. 1, pp. 55-66, 2006.

[30] K. Ryu and H. Sekimoto, "Possibility of highly efficient uranium utilization with a pebble bed fast reactor," Annals of Nuclear Energy, vol. 27, no. 12, pp. 1139-1145, 2000.

[31] W. F. G. van Rooijen, J. L. Kloosterman, T. H. J. J. van der Hagen, and H. van Dam, "Fuel design and core layout for a gas-cooled fast reactor," Nuclear Technology, vol. 151, no. 3, pp. 221-238, 2005.

[32] N. G. Kodochigov, N. G. Kuzavkov, Y. P. Sukharev, and S. G. Usynina, "Concept of a gas cooled fast reactor," in Proceedings of the Physics of Fuel Cycles and Advanced Nuclear Systems: Global Developments (PHYSOR '04), pp. 959-962, American Nuclear Society, Chicago, Ill, USA, April 2004.

[33] C. S. Handwerk, M. J. Driscoll, and P. Hejzlar, "Optimized core design of a supercritical carbon dioxide-cooled fast reactor," Nuclear Technology, vol. 164, no. 3, pp. 320-336, 2008. 

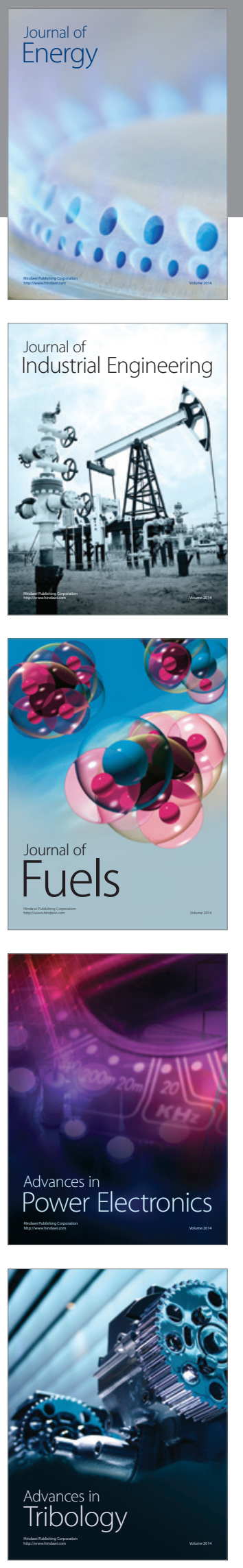
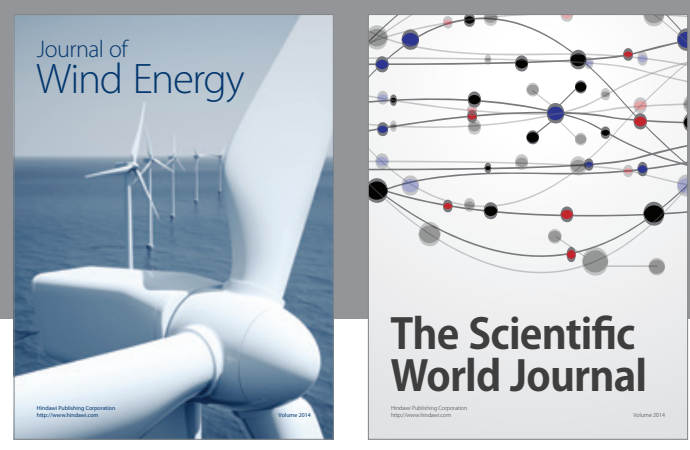

The Scientific World Journal

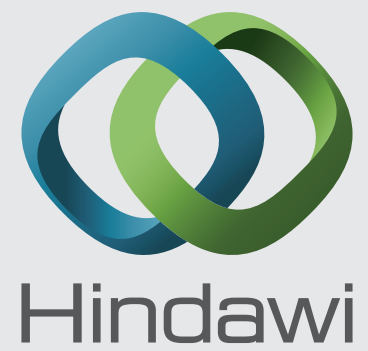

Submit your manuscripts at http://www.hindawi.com
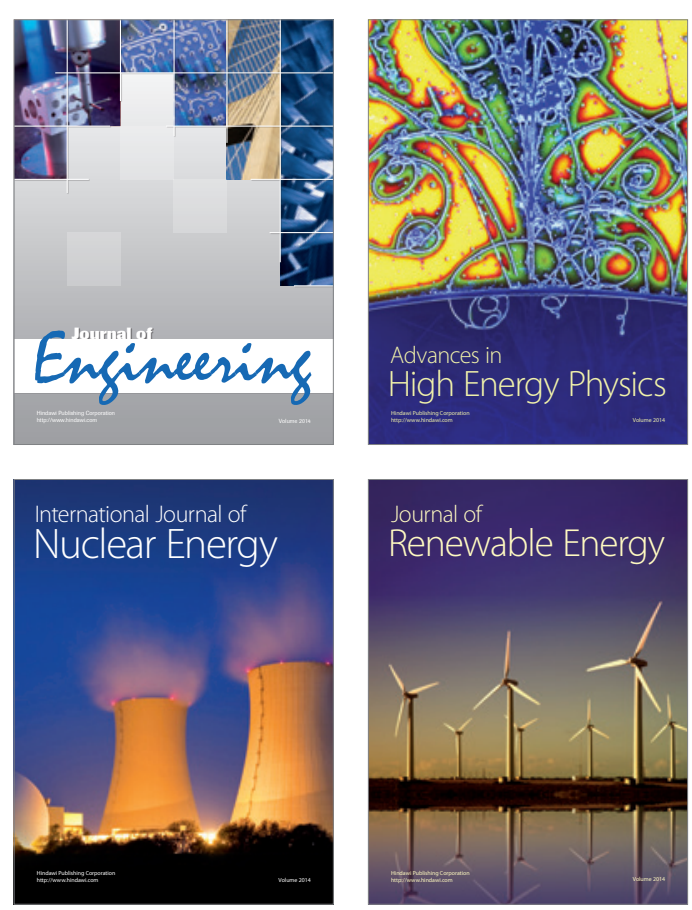

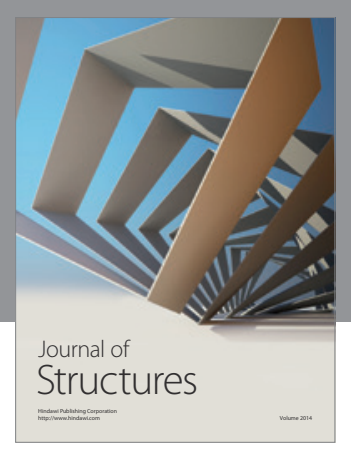

Rotating
Mechinery
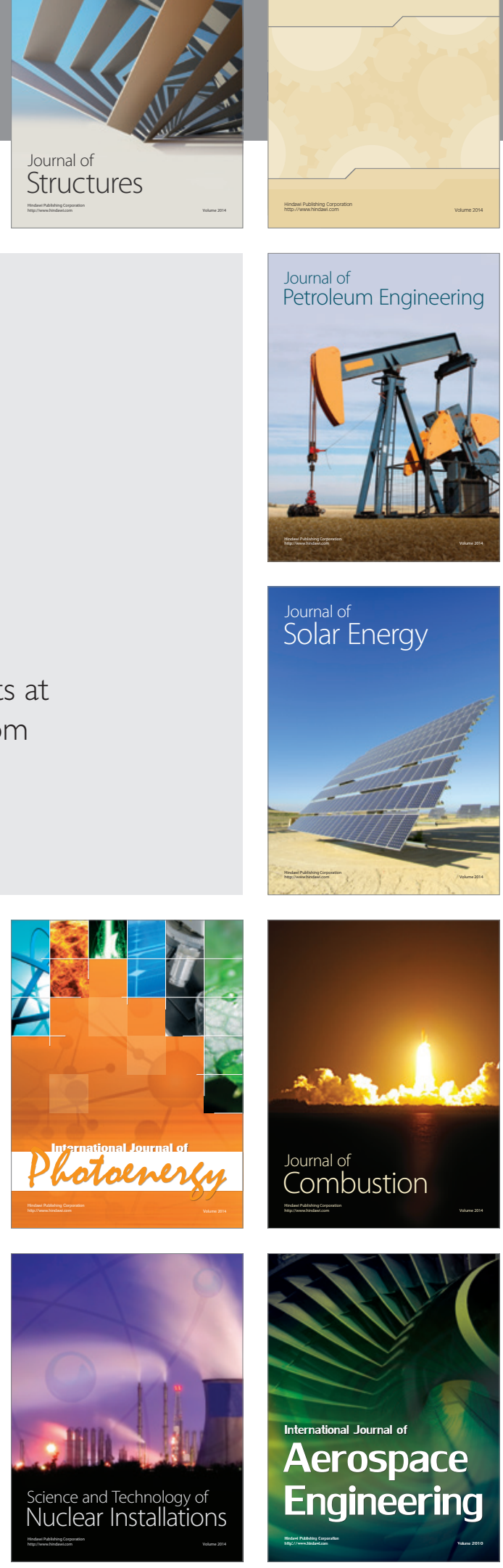